\title{
Strategi TVRI Riau-Kepri Dalam Membangun Budaya Daerah Melalui Program Siaran Budaya Melayu
}

\author{
${ }^{1}$ Dewi Anggraini, ${ }^{2}$ Hayatullah Kurniadi \\ ${ }^{1,2}$ Universitas Islam Negeri Sultan Syarif Kasim Riau \\ Email: dewianggraini990@gmail.com
}

\begin{abstract}
One of the missions of TVRI Riau-Kepri as a public broadcasting institution (LPP) is to build regional culture. It is built by presenting broadcast programs that contain elements of Malay culture. The elements include view of life, art, literature, culinary, clothing, buildings and Malay customary law. The elements of Malay culture are presented on television through broadcast programs by TVRI Riau-Kepri. The purpose of this study is to determine how the strategy of TVRI Riau-Kepri in building regional culture through Malay cultural broadcast programs. This research is qualitative method with data collection using interview, observation and document review. The results show that TVRI Riau-Kepri strategy in building regional culture through Malay cultural broadcast programs is by producing various talkshow (both focus discussion and demonstration). The programs presented cultural observers as speakers who provided information related to life views, arts, clothing, literature and those related to Malay customary law. The preservation of Malay arts also involves musicians from the regions. Besides, there are also documentaries production containing Malay culinary and clothing shows from Riau Province.
\end{abstract}

Keywords: Strategy, TVRI Riau-Kepri, broadcast program, malay culture

\begin{abstract}
Abstrak: Salah satu misi yang ingin diusung oleh TVRI Riau-Kepri sebagai lembaga penyiaran publik (LPP) adalah membangun budaya daerah. Membangun budaya daerah oleh TVRI Riau-Kepri dengan menampilkan program siaran yang mengandung unsur-unsur budaya melayu. Budaya melayu dapat dilihat melalui unsur-unsur yang meliputi pandangan hidup, kesenian, sastra, kuliner, busana, bangunan dan hukum adat melayu. Menampilkan unsur-unsur budaya melayu tersebut di televisi melalui sebuah program siaran, tentu dengan strategi acara yang sudah dipersiapkan oleh TVRI RiauKepri. Tujuan penelitian ini adalah untuk mengetahui bagaimana strategi TVRI Riau-Kepri dalam membangun budaya daerah melalui program siaran budaya melayu. Penelitian ini berjenis kualitatif dengan pengumpulan data menggunakan metode wawancara, observasi dan penelusuran dokumen. Hasil penelitian menunjukkan bahwa strategi TVRI Riau-Kepri dalam membangun budaya daerah melalui program siaran budaya melayu yaitu dengan membuat beragam program talkshow (baik membahas secara detail maupun memperagakan) yang menghadirkan budayawan-budayawan sebagai narasumber yang memberikan informasi yang barkaitan dengan pandangan hidup, kesenian, busana, sastra dan yang berkaitan dengan hukum adat melayu. Menjaga kesenian melayu juga dengan melibatkan musisi-musisi dari daerah-daerah, serta bentuk yang lain adalah dengan pembuatan dokumenter yang berisikan tayangan kuliner dan busana melayu dari Provinsi Riau.
\end{abstract}

Kata kunci: Strategi, TVRI Riau-Kepri, program siaran, budaya melayu

\section{Pendahuluan}

Media massa sebagai media publikasi merupakan media yang tepat dalam menjangkau masyarakat luas. Media dapat memperkenalkan dan menampilkan berbagai macam budaya nasional yang merupakan identitas bangsa. Di samping itu media massa dalam memuat berita 
dan menayangkan berbagai materi acara harus cerdas terutama kesesuaian dengan budaya kepribadian bangsa atau tidak. Semua elemen masyarakat, pemerintah, hingga media massa ikut andil dalam melestarikan budaya yang ada di Indonesia. Media sebagai saluran dalam menyampaikan informasi salah satunya tentang budaya di Indonesia, baik media cetak maupun elektronik, yaitu mengenai budaya dari berbagai daerah. Dari media, masyarakat dapat mengenal lebih jauh tentang budaya tradisional suatu daerah dan secara tidak langsung menaikkan citra budaya lokal serta mencintai budaya sendiri.

Media penyiaran mempunyai karakteristik yang unik atau spesifik dibandingkan dengan media cetak atau media massa yang lainnya. Melalui media penyiaran, informasi dapat diterima pemirsa secara langsung atau biasa disebut dengan realtime atau live. Semua kejadian atau peristiwa dapat secara langsung pada saat yang sama didengar/ dilihat oleh pendengar/ pemirsa dengan cakupan populasi yang sangat luas dan efektif, tetapi informasi yang disampaikan oleh media penyiaran sudah langsung berlalu dan tidak dapat berulang lagi kecuali memang disiarkan ulang. Sementara pada media cetak, informasi yang diberikannya masih dapat dibaca kembali di mana dan kapan saja (Djamal \& Fachruddin, 2013).

TVRI Riau-Kepri hadir untuk memenuhi kebutuhan masyarakat di Riau dan sekitarnya dengan menampilkan program-program siaran yang mampu meningkatkan ketahanan budaya melayu dalam menghadapi era globalisasi, serta sesuai dengan kebutuhan masyarakat di Riau, di mana masyarakat Riau dapat menonton program yang menyiarkan informasi mengenai daerah setempat yang tidak ditayangkan oleh televisi nasional. Sejak Tahun 2007, TVRI Riau-Kepri sudah melayani masyarakat Pekanbaru dan sekitarnya dengan program-program acara yang memang berpihak pada budaya dan kearifan lokal masyarakat Riau. Tugas TVRI Riau-Kepri sebagai media massa adalah berupaya melestarikan budaya lokal, sehingga budaya melayu tidak ditinggalkan oleh budaya-budaya yang baru (Putra \& Nasution, 2016). Penelitian ini bertujuan untuk mengetahui bagaimana strategi TVRI Riau-Kepri dalam membangun budaya daerah melalui program siaran budaya melayu.

Terdapat beberapa penelitian yang mengangkat strategi TVRI yang berkaitan dengan siaran dan penayangan kebudayaan lokal di TVRI sebagai subjek risetnya, seperti yang dilakukan oleh Maulana, di mana hasil penelitian menunjukkan bahwa TVRI Makassar dalam mempertahankan eksistensi program Daeng Mampo dengan strategi: (a) Pengelolaan oleh sumber daya yang profesional dibidangnya dan telah memiliki pengalaman yang lama dalam memproduksi program tersebut, (b) Pengemasan yang mengusung konsep budaya lokal, yaitu Bugis Makassar menjadikan program ini menarik dan dekat dengan masyarakat Sulawesi Selatan dan (c) Dengan menjalin kemitraan (Maulana, 2016). Penelitian lain dilakukan Ersyad \& Murfianti menjelaskan bahwa strategi program TVRI Jawa Tengah dalam meningkatkan kualitas melalui konten budaya pada Tepo Tulodho dengan menggunakan pola yang dinamis. Produksi program sendiri lebih banyak mendominasi dari pada pembelian program. Pengawasan dan evaluasi program dilakukan dalam rapat evaluasi. Strategi budaya lokal dalam program Tepo Tulodho mencakup dua strategi, yaitu: penataan artistik dan konsep visualisasi (pikturisasi) (Ersyad \& Murfianti, 2012). Selanjutnya penelitian yang dilakukan oleh Haulah Citra Kusuma Wardhani tentang strategi pemograman lembaga penyiaran publik TVRI. Hasil penelitian menunjukkan bahwa strategi manajemen programming TVRI meliputi beberapa tahapan, mulai dari perencanaan, produksi dan pembelian, eksekusi hingga pengawasan dan evaluasi program. Proses manajemen programming ini terlihat pada tahapan eksekusi program yaitu saat jam tayang prime time, hampir semua televisi swasta nasional menyangkan program serupa, yaitu sinetron dan variety show, TVRI melakukan kebijakan yaitu dengan menempatkan program dengan segmentasi audience yang lebih spesifik. Konten yang diusung tetap sesuai dengan visi misi program TVRI sebagai lembaga penyiaran publik (LPP) (Wardhani, 2014). 
TVRI Riau-Kepri mengelompokkan mata acara menjadi empat bagian, yaitu: pendidikan, informasi, hiburan dan budaya. Fokus peneliti di sini hanya berkatian dengan konten (siaran) budaya, dalam hal ini adalah budaya lokal (melayu) yang disiarkan oleh TVRI Riau-Kepri. Melayu dapat dilihat pengertian sempit maupun luas. Secara sempit adalah etnis yang berbahasa dan beradat istiadat melayu serta agama Islam yang mendiami wilayah kawasan pantai di Sumatera, Kalimantan dan beberapa kantong di pulau nusantara, yang disebut kampung melayu. Sedangkan dalam pengertian luas adalah yang selama ini dipakai oleh pakar-pakar antropologi yang memandang dari sudut asal muasal awal, yang mempunyai budaya melayu, yaitu seperti yang terlihat dari bahasa, perilaku, karya material dan peralatan maupun bentuk fisik tubuh (Hamidy \& Ahmad, 1993). Unsur-unsur budaya melayu yang dijadikan patokan dalam penelitian ini adalah menyangkut hal-hal sebagai berikut: pandangan hidup melayu, kesenian melayu, sastra melayu, kuliner melayu, busana melayu, bangunan melayu dan hukum adat melayu. Unsur-unsur ini yang ditayangkan oleh TVRI Riau-Kepri melalui program-program yang sudah direncanakan dengan format tertentu.

Dengan adanya program acara budaya lokal, program ini tentu dibuat berdasarkan realitas masyarakat Riau untuk memiliki pengetahuan tentang budaya melayu. Penayangan program ini dapat mempengaruhi pandangan dan membangun pola pikir masyarakat tentang budaya melayu. Untuk memenuhi keinginan tersebut, maka TVRI Riau-Kepri memiliki strategi agar dapat selalu membangun budaya lokal melalui program siaran yang dapat menarik minat masyarakat dan dapat menjadi informasi bagi masyarakat mengenai budaya melayu.

\section{Metode}

Penelitian ini berjenis kualitatif. Peneliti mendeskripsikan strategi TVRI Riau-Kepri dalam membangun budaya daerah melalui program siaran budaya melayu. Pengumpulan data dilakukan dengan wawancara, observasi dan penelusuran dokumen. Wawancara dilakukan kepada kepala program TVRI Riau-Kepri, produser pelaksana dan pengarah acara. Observasi dilakukan dengan melihat berbagai kegiatan yang dilakukan oleh pihak TVRI Riau-Kepri. Penelusuran data juga dilakukan dengan menelusuri dokumen-dokumen yang berhubungan dengan objek penelitian. Analisis data menggunakan model interaktif karya Miles dan Huberman, yaitu pengumpulan data, reduksi data, penyajian data dan penarikan kesimpulan (Sugiyono, 2013).

\section{Hasil dan Pembahasan}

TVRI Stasiun Riau merupakan Stasiun Produksi yang terakhir berdasarkan urutan peresmian Stasiun TVRI yang ada di Pulau Sumatera. Dengan kata lain, daerah Riau merupakan daerah yang paling terakhir memiliki Stasiun Produksi diantara tujuh Provinsi di Sumatera yang telah memiliki stasiun penyiaran dan stasiun produk. TVRI Stasiun Riau secara perlahan mengupayakan peningkatan mutu dan penambahan menu program siaran yang disajikan setiap harinya mulai dari jam 15.00 WIB sampai dengan jam 19.00 WIB (Desfitri, 2017). Jangkauan TVRI Riau-Kepri meliputi, kota Pekanbaru, Dumai, kabupaten Kuantan Sengingi, Indragiri Hulu, Pelalawan, Indragiri Hilir, Kampar, Bengkalis, Siak, Rokan Hilir, Rokan Hulu dan Kepulauan Meranti (TVRI Riau Kepri, 2018).

Program atau acara yang disajikan adalah faktor yang membuat audien tertarik untuk mengikuti siaran yang dipancarkan stasiun penyiaran baik radio ataupun televisi (Morissan, 2009). Sehingga untuk mengetahui bagaimana strategi TVRI Riau-Kepri membangun budaya lokal adalah dengan mengetahui strategi yang dilakukan dalam program siaran budaya lokal 
tersebut. Strategi yang dilakukan oleh Strategi TVRI Riau-Kepri dalam membangun budaya lokal melalui program siaran merupakan tipe strategi program sebagaimana yang diungkapkan oleh Koteen yaitu strategi program (program strategy) dengan memberikan perhatian pada implikasi-implikasi strategis dari suatu program tertentu (Winardi, 2003).

Membangun budaya daerah melaui program siaran budaya melayu memerlukan strategi yang sudah dipikirkan secara baik dari manajemen perusahaan, dengan terus memproduksi program-program budaya lokal yang berkualitas. Hal ini tentu sebagai wujud untuk mencapai misi TVRI Riau-kepri, yaitu menyelenggarakan siaran yang mendidik, menghibur, serta memberi pelayanan informasi yang sehat dan berimbang, dalam membangun budaya daerah dan sebagai kontrol sosial (TVRI Riau Kepri, 2018).

Aspek pertama yang berhubungan dengan unsur budaya melayu yang ditayangkan di TVRI Riau-Kepri adalah pandangan hidup. Pandangan hidup merupakan sebuah kristalisasi dari nilai-nilai yang dimiliki dan diyakini kebenarannya sehingga menimbulkan tekad untuk mewujudkan sesuatu yang menjadi tujuan akhirnya (Briando \& Embi, 2019). Melayu sebagai identitas kultural, biasanya diasosiakam dengan beragama islam, beradat istiadat melayu, dan menempati kawasan melayu. Dalam tayangan program budaya lokal TVRI Riau-Kepri, menampilkan berbagai bentuk unsur yang disampaikan berupa tarian, kesenian, pakaian, musik, bangunan dan sastra melayu.

Gambar 1. Narasumber Dalam Talk Show Acara Melayu

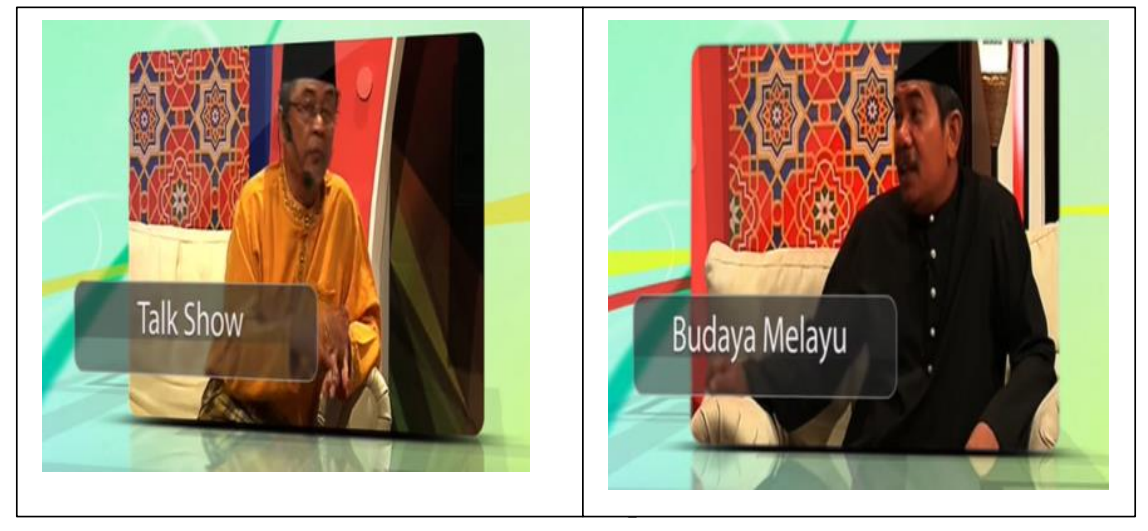

Sumber: Dokumentasi TVRI Riau-Kepri

Strategi dalam mempertahankan pandangan hidup melayu melalui siaran di TVRI RiauKepri adalah dengan dengan membuat program talkshow, yaitu dengan mengundang budayawan-budayawan Riau yang memang mengerti dengan pandangan hidup melayu. Dengan strategi penggunaan narasumber tersebut, maka informasi tentang pandangan hidup melayu dapat dikupas secara mendalam oleh narasumber. Program siaran tersebut dapat memperkenalkan budaya melayu tidak hanya bagi masyarakat melayu di Riau tetapi juga masyarakat lain di luar Riau yang menonton program tersebut.

Aspek kedua yaitu berhubungan dengan kesenian melayu. Kesenian melayu adalah ekspresi dari kebudayaan masyarakat melayu. Di dalamnya terkandung sistem nilai Melayu, yang dijadikan pedoman dan tunjuk ajar dalam berkebudayaan (Takari, 2013). Strategi TVRI Riau-Kepri dalam menampilkan kesenian melayu, di antaranya adalah dengan mengolaborasikan program kesenian melayu dengan program informasi sekaligus, dengan mengundang musisi-musisi dari berbagai daerah untuk menampilkan kesenian di daerah tersebut dan membuat film dokumenter mengenai kesenian melayu. Strategi mengolaborasikikan program kesenian melayu dengan program informasi sekaligus dapat akan mudah diingat oleh masyarakat atau audien, begitu juga dengan adanya tayangan film 
dokumenter mengenai kesenian melayu juga salah satu cara bagaimana kesenian melayu dikenal oleh masyarakat luas.

Gambar 2. Program Siaran yang Menampilkan Kesenian Melayu

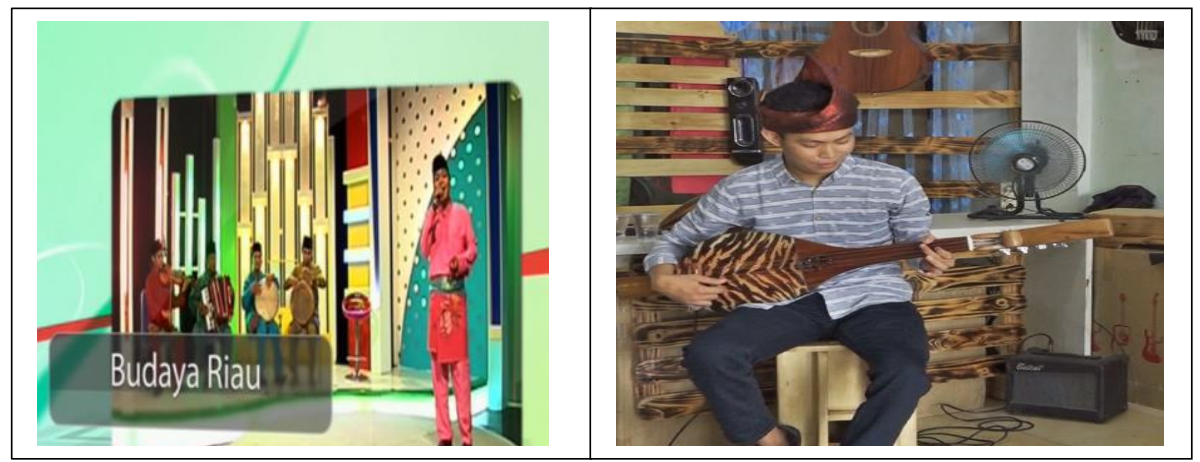

Sumber: Dokumentasi TVRI Riau-Kepri

Aspek berikutnya yang dapat dilihat berhubungan dengan kuliner khas melayu. Kuliner adalah suatu bagian hidup yang erat kaitannya dengan konsumsi makanan sehari-hari karena setiap orang memerlukan makanan yang sangat dibutuhkan sehari-hari (Fauzi, 2014). Strategi TVRI Riau-Kepri dalam mempertahankan kuliner melayu, yaitu dengan membuat program baik berupa talkshow maupun dokumenter yang menampilkan kuliner khas dari daerah-daerah di Riau dengan mendatangkan langsung ahli dalam kuliner tersebut atau dengan datang ketempat pembuatan kuliner tersebut.

Gambar 3. Siaran yang Menampilkan Kuliner Melayu

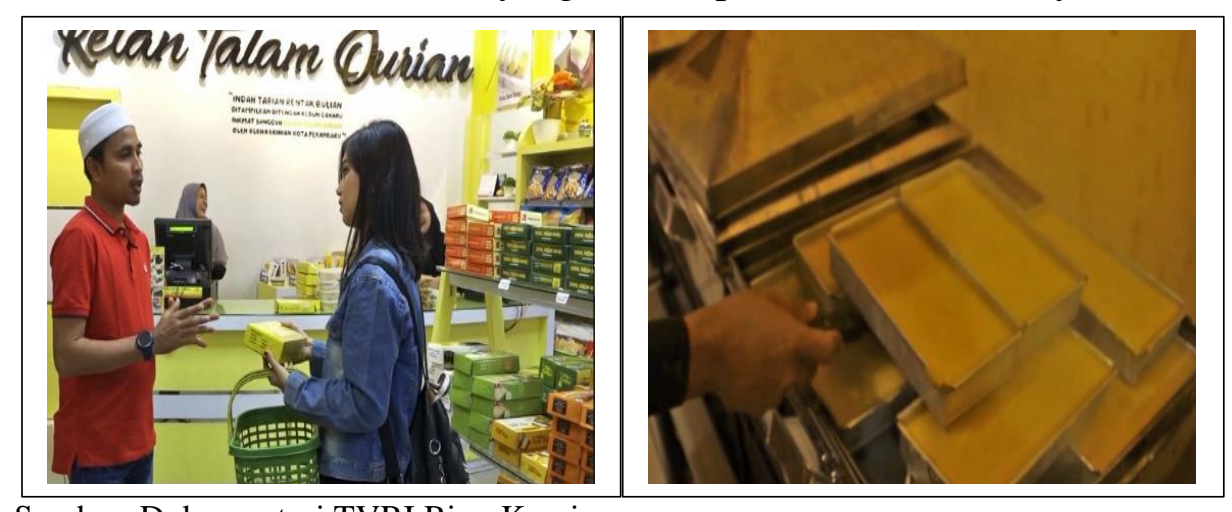

Sumber: Dokumentasi TVRI Riau-Kepri

Seperti diketahui bahwa masing-masing daerah memiliki kuliner yang khas. Namun tidak semua orang mengenalnya. Dengan adanya program siaran tentang kuliner melayu yang ditayangkan oleh TVRI Riau-Kepri merupakan salah satu cara untuk memperkenalkan kuliner tersebut. Apalagi TVRI Riau-Kepri menampilkan ahli-ahli kuliner melayu, hal tersebut tentu akan menambah daya tarik tersendiri dan audien pun mudah mengingatnya. Selanjutnya film dokumenter yang menampilkan makanan khas dan proses pembuatannya juga merupakan salah satu cara memperkenalkan kuliner melayu. Film dokumenter ini juga sebagai media untuk mempromosikan kuliner khas melayu. Hal ini juga dapat memberikan keuntungan bagi pemilik usaha yang memproduksi kuliner tersebut.

Aspek berikutnya adalah berhubungan dengan pakaian daerah Riau. Pakaian merupakan simbol budaya yang menandai perkembangan akulturasi dan kekhasan budaya tertentu. 
Pakaian dapat pula menjadi penanda bagi pemikiran masyarakat, termasuk pakaian tradisional melayu Riau. Pakaian daerah Riau bagi kebanyakan orang melayu di Riau, fungsi dari pakaian selain untuk penutup aurat, melindungi badan aurat dari teriknya panas serta udara dingin, pakaian daerah Riau juga memiliki lambang, lambang-lambang yang terdapat dari pakaian tersebut memiliki niai-nilai yang luhur yang dijunjung tinggi oleh masyarakat Melayu Riau (Ihsani, 2017).

Gambar 4. Program yang Menampilkan Busana Melayu

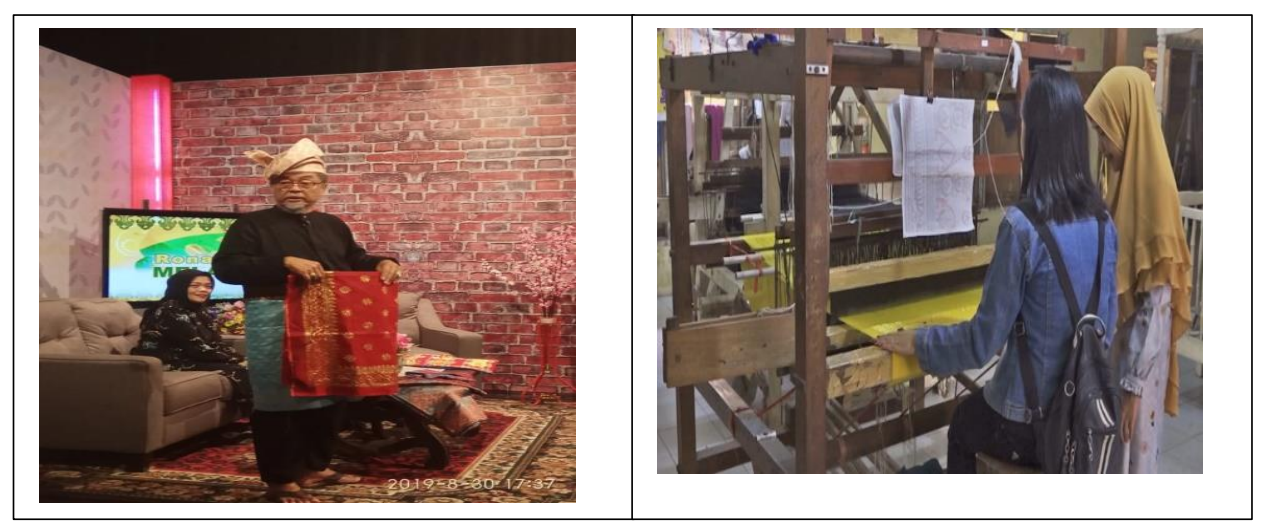

Sumber: Dokumentasi TVRI Riau-Kepri

Strategi TVRI Riau-Kepri dalam mempertahankan busana melayu dengan membuat program siaran berupa talkshow dan dokumenter. Tayangan talkshow sangat memungkinkan untuk memperkenalkan busana melayu, selain audien mendapatkan informasi langsung mengenai busana tersebut, juga audien dapat melihat secara langsung peragaan busana pada program siaran tersebut. Kemudian dengan adanya film dokumenter akan mempermudah audien untuk melihat bagaimana proses pembuatan busana tersebut.

Strategi yang dilakukan oleh TVRI Riau-Kepri untuk mempertahankan busana melayu yang dilakukan secara talkshow dan dokumenter juga sudah tepat untuk mempertahankan busana melayu. Dengan adanya program siaran tersebut masyarakat yang belum mengenal busana melayu dapat mengetahuinya. Apalagi program siaran dilakukan peragaan langung bagaimana cara menggunakannya busana tersebut. Begitu juga dengan fiml dokumenter yang menampilkan produksi busana melayu. Hal tersebut sekalian sebagai promosi untuk memperkenalkan budaya melayu.

Aspek berikutnya berhubungan dengan bangunan melayu. Rumah bagi orang melayu, tidak semata tempat berlindung dari hujan dan panas, tetapi memiliki makna-makna tertentu dan sebagai lambang kesempurnaan hidup. Dalam ungkapan Melayu, rumah dapat dimaknai sebagai: cahaya hidup di bumi, tempat beradat berketurunan, tempat berlabuh kaum kerabat, tempat singgah dagang lalu dan hutang orang tua kepada anaknya (Zaini, 2017).

Apabila dilihat dari fungsinya, bangunan melayu tradisional dapat dikelompokkan menjadi lima, yaitu rumah tempat tinggal, rumah adat, balai pertemuan, tempat ibadah dan tempat penyimpanan. Jika bangunan melayu tradisional dapat dikelompokkan, maka bangunan melayu kontemporer tidak demikian adanya, karena sudah bersifat multifungsi dan telah mengalami akulturasi budaya seperti stilisasi pada bagian-bagian tertentu. oleh karena itu rumah kediaman boleh saja berfungsi sebagai rumah pertemuan, rumah balai, perpustakaan, tempat penelitian atau tempat pengembangan ilmu pengetahuan (Ihsani, 2017). 
Gambar 5. Program yang Menampilkan Rumah Adat Melayu

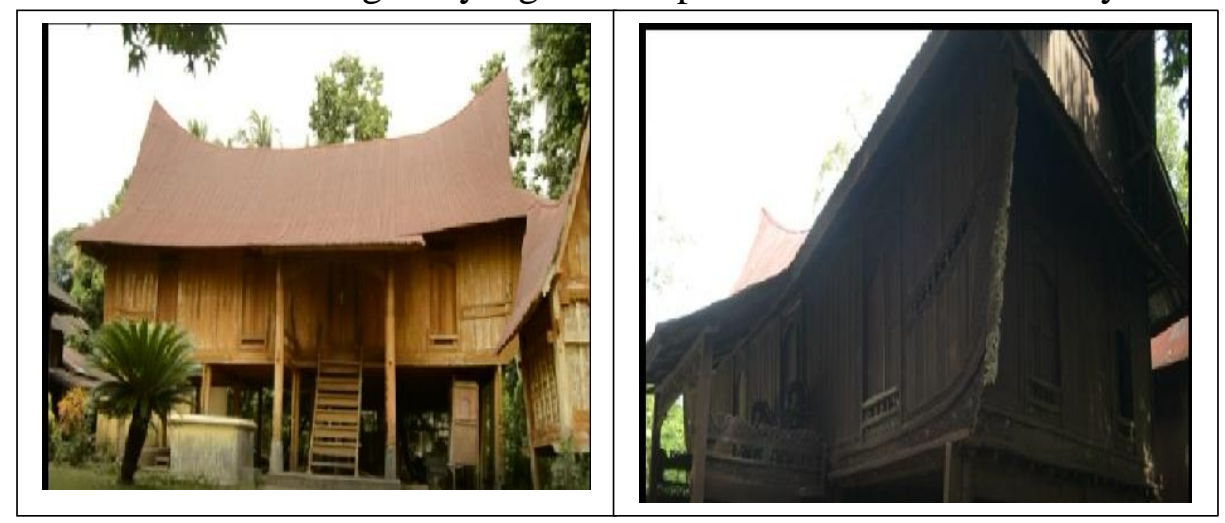

Sumber: Dokumentasi TVRI Riau-Kepri

Berdasarkan hasil penelitian dapat diketahui bahwa strategi TVRI Riau-Kepri dalam mempertahankan bangunan melayu dengan membuat program siaran film dokumenter yang menampilkan bangunan melayu beserta fungsi dan asal usulnya. Program siaran dokumenter yang dibuat oleh TVRI Riau-Kepri sudah merupakan salah satu cara untuk mempertahankan bangunan melayu. Program siaran bangunan melayu memang seharusnya dalam bentuk dokumenter, hal ini disebabkan kalau program siarannya ditampilkan dalam bentuk talkshow akan menyulitkan audien atau masyarakat menerima informasi tersebut. Dengan film dokumenter audien atau masyarakat dapat melihat bagaimana bentuk bangunan tersebut.

Bentuk berikutnya adalah yang berhubungan dengan sastra melayu. Kesusastraan melayu dapat didefinisikan sebagai himpunan hasil-hasil sastra yang menggunakan bahasa melayu sebagai mediumnya, yang berwujud tulisan maupun lisan dan hidup serta berkembang di kawasan persebaran bangsa, dan bahasa melayu (Ihsani, 2017). Riau memiliki banyak karya sastra, namun seiring perkembangan zaman karya sasta melayu mulai dilupakan terlebih lagi para generasi muda. Peran TVRI Riau-Kepri sangat diperlukan untuk mempertahankan sastara melayu tersebut terutama dalam pembuatan program siaran, sebagaimana hasil wawancara berikut ini:

"Karya sastra melayu disajikan dalam program siaran yang menampilkan budayawan-budayawan yang mengenal seluk beluk sastra melayu. Pada program tersebut narasumber akan menjelaskan bagaimana sastra melayu tersebut, jika memungkinkan dilakukan tampilan langsung, misalnya penampilan model yang membawakan syair dan lain-lain" (wawacara dengan Mulyadi).

Berdasarkan wawancara yang dilakukan kepada Mulyadi tersebut dapat dipahami bahwa salah satu cara TVRI Riau-Kepri dalam mempertahankan sastra melayu adalah dengan membawa budayawan sebagai narasumber pada program siaran yang khusus mengenai budaya lokal. Program siaran mengenai sastra melayu yang ditampilkan TVRI Riau-Kepri dengan menampilkan budayawan sebagai narasumber yang mengetahui tentang seluk beluk sastra melayu merupakan salah satu cara mempertahankan agar sastra melayu tetap dikenal dan diketahui oleh masyarakat luas.

Aspek terakhir adalah berhubungan dengan hukum adat melayu. Dalam membuat program siaran tentang hukum adat melayu, TVRI Riau-Kepri mempunyai strategi, seperti yang hasil wawancara berikut ini:

"Masyarakat melayu memiliki adat tersendiri, di mana adat tersebut mempunyai

hukum dan sanksi yang diberikan kepada sesorang yang melanggar adat adalah 
dengan cara memberikan hukuman adat. Hal ini sangat penting untuk generasi muda yang belum memahami betul mengenai hukum adat melayu. Untuk itu sebagai telivisi publik, peran kami sangat penting untuk memberitahukannya, untuk itu program siaran yang menyangkut mengenai hukum adat melayu sangat penting. Sehingga strategi yang digunakan untuk program ini dilakukan sama seperti program sebelumnya yaitu menampilkan narasumber yang memahami betul mengenai masalah tersebut" (wawancara dengan Mulyadi).

Berdasarkan hasil wawancara tersebut dapat diketahui bahwa strategi TVRI Riau-Kepri dalam mempertahankan hukum adat melayu adalah dengan menampilkan program siaran dengan mengundang narasumber yang paham mengenai hukum adat melayu. Strategi TVRI Riau Kepri dalam mempertahankan hukum adat melayu dengan cara mengundang narasumber yang memahami hal tersebut. Narasumber akan memberikan pemahaman kepada masyarakat bagaimana hukum adat melayu, di samping itu informasi ini juga sangat berguna untuk masyarat untuk tidak melanggar hukum adat.

\section{Simpulan}

Dari pembahasan di atas dapat disimpulkan bahwa strategi TVRI Riau-Kepri dalam mempertahankan pandangan hidup melayu, yaitu dengan membuat program siaran berbentuk talkshow yang menghadirkan budayawan sebagai narasumber yang memberikan informasi mengenai hal tersebut. Strategi TVRI Riau-Kepri dalam mempertahankan kesenian melayu yaitu dengan membuat program siaran berbentuk talkshow yang mengolaborasikan dengan musisi dari daerah-daerah. Strategi TVRI Riau-Kepri dalam mempertahankan kuliner melayu yaitu dengan membuat program siaran berbentuk talkshow dan film dokumenter. Pada acara talkshow ditampilkan kuliner-kuliner khas dan cara pembuatannya, sedangkan pada film dokumenter dengan cara mengunjungi lokasi pembuatan kuliner. Strategi TVRI Riau-Kepri dalam mempertahankan busana melayu yaitu dengan membuat program siaran berbentuk talkshow dan film dokumenter. Pada acara talkshow ditampilkan peragaan busana melayu, sedangkan pada film dokumenter lebih ditegaskan cara pembuatannya. Strategi TVRI RiauKepri dalam mempertahankan busana melayu yaitu dengan membuat program siaran berbentuk film dokumenter yang menampilkan bangunan melayu yang ada di Riau. Strategi TVRI Riau-Kepri dalam mempertahankan sastra melayu yaitu dengan membuat program siaran berbentuk talkshow, di mana pada acara tersebut mendatangkan budayawan sebagai narasumber yang ahli dalam sastra melayu dan terakhir strategi TVRI Riau-Kepri dalam mempertahankan hukum adat melayu melalui program siaran adalah dengan mengundang budayawan sebagai narasumber yang ahli dalam hukum adat melayu.

\section{Referensi}

Briando, B., \& Embi, M. A. (2019). Pandangan Hidup dan Alam Pikiran Orang Melayu. Oetoesan-Hindia: Telaah Pemikiran Kebangsaan, 1(2), 69-78. https://doi.org/10.34199/oh.1.2.2019.003

Desfitri, N. (2017). Proses Produksi Program Akademi Da'i Cilik di LPP TVRI Stasiun RiauKepri. Skripsi Universitas Islam Negeri Sultan Syarif Kasim Riau.

Djamal, H \& Fachruddin, A. (2013). Dasar-Dasar Penyiaran: Jakarta: Kencana Prenada Media Group

Ersyad, F. A., \& Murfianti, F. (2012). Strategi Program TVRI Jawa Tengah Dalam Meningkatkan Kualitas Melalui Konten Budaya Pada Tepo Tulodho. Jurnal Seni Media Rekam, 3(2), 39-57. 
Fauzy, A. (2014). Pembangunan Sistem Rekomendasi Pencarian Menu Masakan di Restaurant. Skripsi Universitas Atma Jaya Yogyakarta. http://ejournal.uajy.ac.id/5655/

Hamidy, U. U., \& Ahmad, M. (1993). Beberapa Aspek Sosial Budaya Daerah Riau. Pekanbaru: UIR Press.

Ihsani, D. (2017). Peranan LPP TVRI Riau-Kepri Dalam Memperkenalkan Budaya Riau. Skripsi Universitas Islam Negeri Sultan Syarif Kasim Riau.

Morrisan. (2009). Manajemen Media Penyiaran: Strategi Mengelola Radio dan Televisi. Jakarta: Kencana Prenada Media Group.

Putra, T. R., \& Nasution, B. (2016). Manajemen Program Acara Rona Melayu Di Televisi Republik Indonesia (TVRI) Riau-Kepri Dalam Melestarikan Kebudayaan Melayu. Jurnal Online Mahasiswa (JOM) Bidang Ilmu Sosial Dan Ilmu Politik, 4(1), 1-15.

Sugiyono. (2013) Metode Penelitian Kuantitatif Kualitatif Dan R\&D. Bandung: Alfabeta.

Takari, M. (2013). Kesenian Melayu: Kesinambungan, Perubahan, dan Strategi Budaya. Makalah Dalam Seminar Budaya Melayu. Batam.

Wardhani, H. C. K. (2014). Strategi Pemrograman Lembaga Penyiaran Publik TVRI. Jurnal Unair. http://journal. unair. ac. id/filerPDF/comme56d9 5f0c0full. pdf.

Winardi. (2003). Manajemen Perilaku Organisasi. Jakarta: Kencana Prenada Media Group.

Zaini, M. (2017). Mengenal Rumah Melayu Riau. Jakarta: Badan Pengembangan dan Pembinaan Bahasa, Kementerian Pendidikan dan Kebudayaan. 